\title{
Article
}

\section{Use of Residential Care in Europe for Children Aged Under Three: Some Lessons from Neurobiology}

\author{
Bilson, Andrew
}

Available at http://clok.uclan.ac.uk/1968/

Bilson, Andrew (2009) Use of Residential Care in Europe for Children Aged Under Three: Some Lessons from Neurobiology. The British Journal of Social Work, 39 (7). pp. 1381-1392. ISSN 0045-3102

It is advisable to refer to the publisher's version if you intend to cite from the work. http://dx.doi.org/10.1093/bjsw/bcp076

For more information about UCLan's research in this area go to http://www.uclan.ac.uk/researchgroups/ and search for < name of research Group>.

For information about Research generally at UCLan please go to http://www.uclan.ac.uk/research/

All outputs in CLoK are protected by Intellectual Property Rights law, including Copyright law. Copyright, IPR and Moral Rights for the works on this site are retained by the individual authors and/or other copyright owners. Terms and conditions for use of this material are defined in the policies page. 


\title{
Use of Residential Care in Europe for Children Aged under Three: Some Lessons from Neurobiology
}

\begin{abstract}
This critical commentary reviews the research into the use of residential care for children aged under three years and looks at some of the explanations that can be found for this in neurobiology. There continue to be high numbers and rates of these vulnerable children in institutions not only in the former soviet states but also in Western Europe. The new research provides strong evidence on the negative consequences for these children, particularly for those who remain in institutional care beyond the age of six months. Explanations from neurobiology sit well beside understandings drawn from attachment theory and start to show the mechanisms for this and also the ability of the brain to compensate.
\end{abstract}

Professor Andy Bilson

School of Social Work

University of Central Lancashire

Email abilson@uclan.ac.uk 


\section{Introduction}

Twenty years ago, at the same time as the inception of the United Nations Convention on the Rights of the Child, many were shocked at the pictures of the suffering of babies and young children in the orphanages of the newly independent state of Romania. This paper considers research into the use of institutional care for very young children in Europe. Whilst research in the United Kingdom in the late 1970s challenged the practice of placement of very young children in institutions and the levels of placement fell rapidly in the 1980s, this paper will show that the use of residential placements for very young children continues in many parts of Europe. The recent research that shows the damage that can be done by this practice is starting to be explained by some of the latest developments and techniques of neurobiology which have implications for a wide range of practice with young children and babies. This research is particularly relevant in England as we see the increase in young children entering the care system in the wake of the Baby Peter tragedy. Whilst the research covered here principally focuses on the institutionalisation of babies the neurobiological insights have wider implications for their care.

\section{The Use of Residential Care for Infants in Europe}

Before moving on to considering the research evidence on the impact of placement of infants in residential care, the paper will first consider the available statistics on the use of residential care across Europe for children under the age of three years. This paper will use a wide definition of Europe based on membership of the Council of Europe. This covers a considerable geographical area extending into Central Asia. It includes many of the new independent states (sometimes referred to as countries in transition) that formerly were part of the Soviet Union. There are no sound comparable statistics for the levels of children in state care ${ }^{1}$ even within the European Union (Ruxton, 2005: 142). Despite the lack of comparable statistics, this section shows the evidence that placement of infants in residential care is still common in countries across Europe and not limited to the new independent states.

The first source of information on levels of use of institutions for children under the age of three comes from a series of papers on a survey carried out with funding from the European Union's Daphne programme. This study was carried out in 31 European countries, not including those that were Russian speaking (Browne et al., 2005; Browne et al., 2006; Chou and Browne, 2008; Johnson et al., 2006). It was based on a census of children in state care in the 2003 calendar year. The census used a high threshold for children in residential care counting only those placed for a period longer than three months and excluded placements of babies with their parents. Additionally an institution was defined as 'a residential, health or social care facility of eleven or more children regardless of age’ (Browne et al., 2005:25). The survey found:

23,099 children, of a population of 20.6 million under 3, in institutions for more than 3 months without a parent. This represents 11 children in every 10,000 under 3 years in residential care institutions. (Johnson et al., 2006: 1)

\footnotetext{
${ }^{1}$ The paper will use this term to cover children who are without parental care and cared for by the state as the legal status and types of accommodation of such children can vary significantly.
} 
Table 1

Population, number and proportion (rate per 10,000) of children under three years in institutional care in 2003

\begin{tabular}{|l|l|l|l|}
\hline Country & Population & $\begin{array}{l}\text { Number in } \\
\text { institutions }\end{array}$ & $\begin{array}{l}\text { Rate per } \\
10,000^{*}\end{array}$ \\
\hline Czech Republic & 270,293 & 1,630 & 60 \\
\hline Belgium & 383,639 & 2,164 & 56 \\
\hline Latvia & 71,2504 & 395 & 55 \\
\hline Bulgaria & 245,704 & 1,238 & 50 \\
\hline Lithuania & 100,268 & 458 & 46 \\
\hline Hungary & 174,893 & 773 & 44 \\
\hline Romania & 877,772 & 2,915 & 33 \\
\hline Slovak Republic & 160,186 & 502 & 31 \\
\hline Finland & 168,370 & 466 & $(28)$ \\
\hline Malta & 16,485 & 44 & 27 \\
\hline Estonia & 37,953 & 100 & 26 \\
\hline Spain & $1,064,764$ & 2,471 & $(23)$ \\
\hline Netherlands & 818,713 & 1284 & 16 \\
\hline Portugal & 434,616 & 714 & 16 \\
\hline France & $2,294,439$ & 2,980 & $(13)$ \\
\hline Poland & $1,490,440$ & 1,3444 & 9 \\
\hline Croatia & 178,142 & 144 & 8 \\
\hline Albania & 166,800 & 13311 & 8 \\
\hline Sweden & 278,400 & 2138 & $(8)$ \\
\hline Denmark & 197,758 & 133 & 7 \\
\hline Germany & $2,232,569$ & 1,495 & 7 \\
\hline Ireland & 166,208 & 959 & $(6)$ \\
\hline Cyprus & 33,339 & 159 & $(4)$ \\
\hline Austria2 & 107,7095 & 37 & 3 \\
\hline Greece & 377,9304 & 114 & 3 \\
\hline Turkey & $4,388,000$ & 850 & 2 \\
\hline Italy & $1,614,667$ & 310 & $(2)$ \\
\hline Norway & 172,877 & 17 & $(<1)$ \\
\hline United Kingdom & $2,037,463$ & 65 & $(<1)$ \\
\hline Iceland & 12,412 & 0 & 0 \\
\hline Slovenia & 53,736 & 0 & 0 \\
\hline Luxembourg & 16,992 & - & - \\
\hline TOTAL & $20,644,787$ & 23,099 & 11.2 \\
\hline & & & \\
\hline
\end{tabular}

For details of any limitations and estimates used in these figures see the original source Browne et al. 2005: 26

* Figures in brackets should be treated with caution - these figures have either been based on estimates from samples of children over the age of five years or include children who may be in institutional care with a parent, for less than three months, or in a facility with less than 11 children.

Based on Browne et al. 2005: 26 
There were considerable variations between countries with four countries having less than 1 child placed per 10,000 aged under three years old and surprisingly, at the other end of the spectrum, as many as eight countries had between 31 and 60 children per 10,000 in residential care (see table 1). Whilst France, Romania, Spain and Belgium had the highest numbers of children placed in institutions (each having over 2,000 children), when the country's population is taken into account the highest rates of use of residential care were found in the Czech Republic, Belgium, Latvia and Bulgaria where more than one in every 200 infants had been in residential care for over three months in 2003 (each country had a rate higher than 50 per 10,000 children under three years old in residential care).

The survey looked at a number of issues including the stated reason for entry to care. It concludes that: 'Children were more often institutionalised in economically developed countries for abuse and neglect whereas, in countries in transition, children were placed in institutional care mainly because of abandonment and disability' (Browne et al., 2005: 30). However it should be remembered that this is the administrative category rather than a reason. The term abandonment covers a range of situations and is often applied to families who give up their child due to their extremes of poverty and social exclusion (see Bilson and Cox, 2007; Bilson and Markova, 2007). In fact the children institutionalised in many of the transition countries covered by this study (particularly Bulgaria, Romania, Hungary, Czech Republic, Slovak Republic) are frequently of Roma origin - a group who have suffered considerable social exclusion including high levels of unemployment, poor housing conditions, as well as their over-representation in institutions of all types (see for example Ringold, 2000; Tobis, 2000; European Commission, 2004; Bilson and Markova, 2007; ERRC, 2007). Similarly, due to issues of segregated education, many Roma in these countries are classified as having a disability in order to gain an education (e.g. in Czechoslovakia in 1997 estimates showed that 64\% of Roma children were in special schools compared with $4.2 \%$ of the overall population: Ringold, 2000).

The second source of data on children in institutions is the UNICEF Innocenti Research Centre's TransMONEE database (UNICEF, 2008). This immensely useful tool captures a wide range of data relevant to the social and economic situation and well-being of children, young people and women of countries in Central and Eastern Europe and the Commonwealth of Independent States (CEE/CIS). This database provides information on 28 new independent states and the 2008 version (UNICEF, 2008) covers the years 1989 to 2006 and 164 economic and social indicators divided into 10 topics (Population, Natality, Child and Maternal Mortality, Life Expectancy and Adult Mortality, Family Formation, Health, Education, Child Protection, Crime and the Economy). The database is published on the internet and each year until 2006 a report was published with an overview of the statistics and a focus on a particular topic. Table 2 shows the data on the numbers and rate of infants in infant homes in 19 countries for which these data are available in the 2008 database. This shows that in these countries there were 37,160 infants in institutional care. The Russian Federation alone has 20,300 children in these institutions. 


\section{Table 2}

Number and rate of children in infant homes (per 10,000 population aged 0-3)

$\begin{array}{llll}\text { Country } & \text { Notes } & \text { Number of children } & \text { Rate of children per 10,000 } \\ \text { Bulgaria } & 1 & 2,743 & 99 \\ \text { Latvia } & 2,3 & 321 & 50 \\ \text { Czech Republic } & 4 & 1,470 & 37 \\ \text { Russian } & & & \\ \text { Federation } & & 20,300 & 35 \\ \text { Lithuania } & 2 & 416 & 34 \\ \text { Belarus } & & 1,214 & 34 \\ \text { Ukraine } & & 4,946 & 29 \\ \text { Moldova } & 5 & 388 & 26 \\ \text { Kazakhstan } & & 2,512 & 23 \\ \text { Hungary } & & 839 & 22 \\ \text { Georgia } & & 222 & 12 \\ \text { TFYR Macedonia } & & 95 & 10 \\ \text { Albania } & & 148 & 8 \\ \text { Kyrgyzstan } & & 213 & 6 \\ \text { Turkmenistan } & & 219 & 5 \\ \text { Armenia } & 6 & 77 & 4 \\ \text { Azerbaijan } & & 142 & 3 \\ \text { Uzbekistan } & & 732 & 3 \\ \text { Tajikistan } & & 163 & 2 \\ \text { Total } & & 37,160 & \end{array}$

1. Children residing in homes for medical and social care, 0-3 year olds.

2. Data for 2005-2006 are taken from web-sites of the Statistical Office.

3. Data include children 0-2 years residing in Social Care Centres for orphaned children and Children's homes.

4. Data include institutions for infants and homes for children under the auspices of the Health Ministry.

5. Data for the period 1992-2006 do not include Transdniestr.

6. Data include children aged 0-5.

Source UNICEF 2008 tables 8.6 and 8.7

Between these two sources of data it can be seen that a substantial number of children aged under three years are in residential care and that, whilst only Belgium has rates at the same level as those found in a number of the new independent states, there are still high numbers in France and Spain. The next section considers the evidence on the impact of institutionalization, particularly in the very deteriorated environments of institutions in countries such as Romania.

\section{Studies of the Impact of Institutionalisation}

The knowledge that early institutionalisation is damaging to children is not new. In the UK in the late 1970s Tizard and her colleagues undertook influential longitudinal research into the impact on young children who had been brought up in institutions for the first two to four years of their lives. They compared four groups that were 
adopted between ages 2 and 4; returned to their biological families between ages 2 and 4; remained institutionalised; and never-institutionalized children of the same age (see, Tizard, 1977; Tizard and Hodges, 1978; Tizard and Reese, 1974, 1975). These children were followed up at various ages until they reached 16 (Hodges and Tizard, 1989a, 1989b). The findings showed that institutionalised children had higher incidence of behavioural and emotional problems than their matched comparisons. At the age of 16 years, between $35 \%$ and $50 \%$ of them had, according to their teachers, some degree of the following difficulties: restlessness, distractibility, quarrelsomeness with peers, irritability, and resentment if corrected by adults. The adopted group who had fared somewhat better than those returned home were displaying signs of anxiety rather than the tendency towards more antisocial types of behaviour in the restored group, though both these groups were more oriented towards adult attention, and had fewer close relationships and more difficulties with peers than matched groups.

More recent studies of Romanian orphans adopted in the United Kingdom (e.g. Rutter et al., 2007) and Canada (e.g. Morrison et al., 1995) have shown similar, but more extreme, long term effects. Rutter et al.(2007) suggest there is 'generally good agreement across studies' (2007: 334) of adopted Romanian orphans. The English and Romanian Adoptees Study looked at a randomly selected sample of 165 children from Romania who were adopted by UK families with placement before the age of 42 months. 144 of them had been reared in institutions. Comparisons were made with a sample of 52 non-institutionalised UK children adopted before the age of 6 months. These groups have so far been studied at 4,6 , and 11 years of age and the study is ongoing. At placement in the adoptive family the institutionalised children suffered a range of severe problems and they were severely developmentally delayed. Marked catch-up in psychological functioning was evident following adoption, but significant problems continued in a substantial minority of the children placed for adoption after the age of 6 months. At the ages of 4 and 6 years it looked as if the amount of harm was mediated by the length of placement in an institution - shorter periods implying lower numbers of children displaying negative outcomes. However, the findings at the age of 11 indicate that the numbers of children showing negative outcomes are similar for all groups of children who were not adopted by the age of six months. Those adopted by six months, despite having significant developmental delays on placement for adoption, were not significantly different from the comparison groups of English adoptees by the age of 11 . However there was a marked jump, to $40 \%$ to $50 \%$ having an impairment of Romanian adoptees from institutions placed anything much over the age of 6 months Kreppner et al. (2007).

The study found a range of negative outcomes including a high rate of autistic-like patterns (Rutter et al., 1999). At the age of four this looked like 'ordinary' autism but, by age six, important differences developed. Firstly there was a reduction in autistic features compared with a longitudinal study of children with 'ordinary' autism. There were also substantial behavioural differences - disinhibited attachment or evidence of poor peer relationships. At the age of eleven almost a quarter of the children lost their autistic features and in another quarter they substantially diminished. However, only a few were free of impairment at this age with most showing a continuation of disinhibited attachment or poor relationships with other children. Additionally, most of these children were receiving some form of special educational or mental health services. 
Another more recent set of studies of children in Romanian orphanages have been carried out by the Bucharest Early Intervention Project and these have been combined with the use of a battery of psychological tests as well as EEG scans to measure brain activity. The project carried out a randomised controlled trial creating a fostering scheme and randomly placing children in foster placements. This is important because it rules out some of the limitations of the more naturalistic designs mentioned above. The project was careful in its assessment of the ethical grounds for the study. Without the research all the children would have remained in the institutions and the research aimed to look at genuinely unexplored questions for which they claimed the experimental design was justified (for a discussion of the ethics of this research see Millum and Emmanuel, 2007). Through studies using PET scans they claim to show that placement in foster care is associated with measurable neurophysiological changes in the brain with the extent being partly determined by the age of placement in foster care (Marshall et al., 2008: 879). The research shows negative effects of institutionalisation on attention and emotion expression (Ghera et al., 2009) and cognition:

The cognitive outcome of children who remained in the institution was markedly below that of never-institutionalized children and children taken out of the institution and placed into foster care. The improved cognitive outcomes ... were most marked for the youngest children placed in foster care. These results point to the negative sequelae of early institutionalization, suggest a possible sensitive period in cognitive development, and underscore the advantages of family placements for young abandoned children. (Nelson et al., 2007: 1937)

These studies relate to children placed in the extreme deprivation of the orphanages in Romania where children were often subjected to major deprivation in particular of human contact. However other studies show the likelihood of negative effects of even 'good' quality care. Johnson et al. (2006) carried out a systematic literature review of research studies of early use of residential care which included a control or comparison group study design and that focussed on three domains: attachment; social and/or behavioural development, and cognitive development. This found that:

Of 12 studies on attachment in children raised in institutional care only one found no supporting evidence for an increase in attachment difficulties. Of 17 studies on social and behavioral development of children, again only one found inconclusive evidence in relation to age of exposure to institutional care. Of 13 studies on cognitive development, all except one report a poorer cognitive performance associated with institutional care. (2006: 22)

The studies covered both 'good' residential care and that of the extremes found in the research such as that above. Unsurprisingly they found that the effects of the very poor environments were considerably worse. However, even 'good' quality care performed more poorly than placement in a family and they concluded: 'the evidence clearly indicates that institutional care does not support the optimal development of children' (Johnson et al., 2006: 23; original emphasis).

\section{Neurobiology and Early Childhood Deprivation}

Developments in our understanding of the brain can provide an explanation of these phenomena and the impact of institutionalisation. The development of the brain in the 
first months of life is truly amazing. At a baby's birth its brain has 100 billion neurons and during the first years of life each of these neurons develops around 15,000 connections every second (Balbernie, 2001). This rich interconnection forms the basis for the development of the infant's brain. The brain, in a display of biological exuberance, produces trillions more connections between neurons than it can possibly use. Following this the brain eliminates connections, or synapses, that are seldom or never used. What provides the chance for synaptic connections to survive is quite simply the degree of their use, and the degree of their use is dependent on the experiences the baby has. Neural pathways that are used become permanent and those that are not used are eliminated. Deprived of a stimulating environment, a child's brain suffers and children who are severely under-stimulated develop brains $20 \%$ to $30 \%$ smaller than normal for their age.

Maturation of the brain seems to have a set order and it does not develop at an even pace. It tends to develop in waves with different parts of the brain developing at different times. This development takes place, however, in a predictable sequence. Between six and eight months, the frontal cortex begins to mature, which continues until the infant is a year old. Even within the frontal cortex, there is a specific order and hierarchy of maturation strongly suggesting that these events are genetically programmed. The functional maturation of the frontal cortex begins in the side and lower portions, later proceeds to the middle, and finally to the dorsal prefrontal areas. Improved cognitive competence coincides with the functional maturation of these frontal cortical regions. Thus, although a typical five-month-old infant is content to play with, smile at, and even be picked up by a stranger, in contrast a typical eight to ten-month-old is cautious, clinging to a parent when a stranger attempts to approach the baby. Schore (2001) draws the parallels between this research into brain development and attachment theory suggesting that the environment needed for healthy brain development in these early years is a secure attachment.

Nelson (2007: 15) draw together some of the findings of the research into the brain development of children who have experienced early institutionalisation. They state that the early studies of brain functioning of institutionalised children undertaken by Eluvathingal et al. (2006) and Chugani et al. (2001), whilst having some limitations because of small sample size and other methodological factors, show that 'these children suffered from metabolic deficits in the areas of the brain believed to be involved in higher cognition, emotion, and emotion regulation'. Both the Rutter and colleagues' studies of Romanian Orphans adopted in the UK and the Bucharest Early Intervention Project found that head circumference and brain volume were smaller in the institutionalised groups. Rutter et al. (2007: 342) attempted to find connections between the difference in size of different parts of the brain and the four deprivationspecific outcomes they found in their study. Whilst needing further study which they intend to carry out, they state:

The findings with respect to mediators of outcome were more complex. Thus, the uncorrected values of the size of the corpus callosum (CC) showed that the Romanian adoptees with one or other of the four relatively deprivation-specific outcomes had a significantly lower CC volume than those without such problems. However, as we have noted, deprivation had a marked effect on overall brain size and it was, therefore, necessary to take that into account ... the significant finding was that the Romanian adoptees without deprivation-specific problems had a larger CC than both 
the controls and the Romanian children with deprivation-specific problems. The implication would seem to be that this increase in size represented a successful compensatory response to deprivation. (emphasis added)

In other words the research found some initial evidence to hypothesise that developmental damage caused by institutionalisation might have been mediated for some children by later developments in the corpus callosum. If this turns out to be substantiated with larger samples, we are seeing not only evidence of damage to the brain but also of a possible compensating mechanism for some children - physical evidence of the resilience of children even when exposed to severe deprivations.

\section{Conclusion}

This research provides further evidence on the long lasting negative consequences of the use of residential care for young children and also on the power of recovery that can be found in a loving relationship. At the same time the linking of the research to developments in neurobiology starts to point to some interesting findings with regard to key developmental periods when children may be more at risk (though no young child should be placed in residential care) and also some evidence of the mechanisms of resilience in children who have been seriously deprived. Chou and Browne's paper (2008) on the association between high numbers of infants in residential care (transition countries with more residential care were more likely to provide children for adoption and those receiving high numbers of adopted children were more likely to have high rates in institutional care) has concluded that the 'evidence does not support the notion that international adoption reduces institutional care. On the contrary, survey data suggest that it may contribute to the continuation of institutional care and the resulting harm to children' (p. 47).

This research has implications not only for transition countries like Kazakhstan where I am sitting writing this, but also for those countries like Belgium, France and Spain that also have large numbers of young children in institutions. It also points to the lessons that social work might learn from the fast moving research in neurobiology which has implications in fields far wider than that concerned with the use of residential care. 


\section{References}

Balbernie, R. (2001) 'Circuits and circumstances: The neurobiological consequences of early relationship experiences and how they shape later behaviour.' Journal of Child Psychotherapy, 27, 237-255

Bilson, A. and Cox, P. (2007) 'Caring about Poverty: Alternatives to institutional care for children in poverty’ Childhood Poverty Vol. 13, No 1 pp. 37-55

Bilson, A. and Markova, G. (2007) 'But you should see their families: Preventing child abandonment and promoting social inclusion in countries in transition' Social Work and Social Science Review Volume 12, Number 3, pp. 57-78

Browne, K., Hamilton-Giachritsis, C., Johnson, R. and Ostergren, M. (2006) 'Overuse of institutional care for children in Europe?’ British Medical Journal 332, pp 485-87

Browne, K, Hamilton-Giachritsis, C., Johnson, R., Chou, S., Ostergren, M., Leth, I., Agathonos-Georgopoulou H., Herczog, M., Keller-Hamela, M., Klimácková, A., Stan, V., and Zeytinoglu, S. (2005) 'A European survey of the number and characteristics of children less than three years old in residential care at risk of harm.' Adoption and Fostering 29:23-33.

Chugani, H. T., Behen, M. E., Muzik, O., Juhasz, C., Nagy, F. and Chugani, D. C. (2001) 'Local brain functional activity following early deprivation: A study of postinstitutionalized Romanian orphans.’ Neuroimage, 14, 1290-1301.

Chou, S. and Browne, K. (2008) 'The relationship between institutional care and the international adoption of children in Europe' Adoption and Fostering 32(1): 40-48

Eluvathingal, T. J., Chugani, H. T., Behen, M. E., Juha'sz, C., Muzik, O., Maqbool, M.,Chungani, D. C., and Makki, M. (2006) 'Abnormal brain connectivity in children after early severe socioemotional deprivation: A diffusion tensor imaging study.' Pediatrics, 117, 2093-2100.

ERRC (2007) Dis-Interest of the Child: Romani Children in the Hungarian Child Protection System, Budapest, European Roma Rights Centre (ERRC)

European Commission (2004) The Situation of Roma in an EnlargedEuropean Union Luxembourg, European Commission

Ghera, M. M., Marshall, P. J., Fox, N. A., Zeanah, C. H., Nelson C. A., Smyke, A. T. and Guthrie, D. (2009) 'The effects of foster care intervention on socially deprived institutionalized children's attention and positive affect: results from the BEIP study' Journal of Child Psychology and Psychiatry 50(3):246-53

Hodges, J. and Tizard, B. (1989a) 'Social and family relationships of ex-institutional adolescents.’ Journal of Child Psychology and Psychiatry, 30(1), 77-97. 
Hodges, J. and Tizard, B. (1989b) 'IQ and behavioural adjustment of ex-institutional adolescents.’ Journal of Child Psychology and Psychiatry, 30 (1), 53-75.

Johnson, R., Browne, K. and Hamilton-Giachritsis, C. (2006) 'Young Children in Institutional Care at Risk of Harm.’ Trauma, Violence, and Abuse, 7(1) 1-26

Kreppner, J., Rutter, M., Beckett, C., Castle, J., Colvert, E., Groothues, C., and Hawkins A. (2007) 'Normality and impairment following profound early institutional deprivation: A longitudinal follow-up into early adolescence.' Developmental Psychology. 43(4): 931-946

Marshall, P. J., Reeb, B.C., Fox N. A., Nelson, C. A. and Zeanah, C. H. (2008) 'Effects of early intervention on EEG power and coherence in previously institutionalized children in Romania.' Development and psychopathology 20(3):86180

Millum, J. and Emmanuel E. J. (2007) 'The Ethics of International Research with Abandoned Children’ Science 318 pp. 1874-1875

Morison, S. J., Ames, E. W., and Chisholm, K. (1995) 'The development of children adopted from Romanian orphanages.’ Merrill-Palmer Quarterly, 41, 411-430

Nelson C.A. (2007) 'A Neurobiological Perspective on Early Human Deprivation.' Child Development Perspectives 1(1): 13-18

Nelson, C. A., Zeanah, C. H., Fox, N. A., Marshall, P. J., Smyke, A. T. and Guthrie, D. (2007) 'Cognitive recovery in socially deprived young children: the Bucharest Early Intervention Project.’ Science 318(5858):1937-40.

Ringold, D. (2000) Roma and the Transition in Central and Eastern Europe: Trends and Challenges The World Bank, Washington

Rutter, M., Beckett, C., Castle, J., Colvert, E., Kreppner, J., Mehta, M., Stevens, S. and Sonuga-Barke, E. (2007) 'Effects of profound early institutional deprivation: An overview of findings from a UK longitudinal study of Romanian adoptees.' European Journal of Developmental Psychology 4(3) pp. 332-350

Rutter, M., Andersen-Wood, L., Beckett, C., Bredenkamp, D., Castle, J., Groothues, C. (1999). 'Quasi-autistic patterns following severe early global privation.' Journal of Child Psychology and Psychiatry, 40, 537 - 549.

Ruxton, S. (2005) What about us? Children's Rights in the European Union Brussels, European Children's Network; accessed on 12/05/2009 from http://www.crin.org/docs/Ruxton\%20Report_WhatAboutUs.pdf

Schore, A. N. (2001) 'Effects of a secure attachment relationship on right brain development, affect regulation, and infant mental health.' Infant Mental Health Journal, 22 (1-2), 7-66.

Tizard, B. (1977) Adoption: A second chance. New York: Free Press. 
Tizard, B., and Hodges, J. (1978) 'The effect of early institutional rearing on the development of eight-year-old children.' Journal of Child Psychology, Psychiatry, and Allied Disciplines, 19, 99-118.

Tizard, B., and Rees, J. (1974) 'A comparison of the effects of adoption, restoration to the natural mother, and continued institutionalization on the cognitive development of four-year-old children.’ Child Development, 45, 92-99.

Tizard, B., and Rees, J. (1975). 'The effect of early institutional rearing on the behavior problems and affectional relationships of fouryear-old children.' Journal of Child Psychology, Psychiatry, and Allied Disciplines, 16, 61-73.

Tobis, D. (2000) Moving from Residential Institutions to Community-based Social Services in Central and Eastern Europe and the Former Soviet Union The World Bank, Washington http://lnweb18.worldbank.org/eca/eca.nsf/Attachments/Moving+from+Residential+In stitutions+to+Community-Based+Social+Services/\$File/14490.pdf

UNICEF (2008) TransMONEE Database Florence, UNICEF International Research Centre Accessed on 12/5/2009 from http://www.unicef-irc.org//databases/transmonee/ 